\title{
The longitudinal development of emotion regulation capacities in children at risk for externalizing disorders
}

Article

Accepted Version

Halligan, S. L., Cooper, P. J., Fearon, P., Wheeler, S. L., Crosby, M. and Murray, L. (2013) The longitudinal development of emotion regulation capacities in children at risk for externalizing disorders. Development and

Psychopathology, 25 (2). pp. 391-406. ISSN 1469-2198 doi: https://doi.org/10.1017/S0954579412001137 Available at https://centaur.reading.ac.uk/26285/

It is advisable to refer to the publisher's version if you intend to cite from the work. See Guidance on citing.

To link to this article DOI: http://dx.doi.org/10.1017/S0954579412001137

Publisher: Cambridge University Press

All outputs in CentAUR are protected by Intellectual Property Rights law, including copyright law. Copyright and IPR is retained by the creators or other copyright holders. Terms and conditions for use of this material are defined in the End User Agreement. 


\section{CentAUR}

Central Archive at the University of Reading

Reading's research outputs online 
Running Head: Emotion regulation and risk for externalizing disorder

The longitudinal development of emotion regulation capacities in children at risk for externalizing disorders

Sarah L. Halligan*, Peter J. Cooper, Pasco Fearon, Sarah L. Wheeler, Michelle Crosby, Lynne Murray

School of Psychology and Clinical Language Sciences, University of Reading

*Correspondence

Sarah L. Halligan

School of Psychology and CLS, University of Reading

3 Earley Gate, Whiteknights

Reading RG6 6AL, UK

Phone: +44 (0)118 3787554

Fax: $\quad+44(0) 1183786665$

Email: s.1.halligan@ reading.ac.uk 
Running Head: Emotion regulation and risk for externalizing disorder

\begin{abstract}
The development of emotional regulation capacities in children at high versus low risk for externalizing disorder was examined in a longitudinal study investigating: a) whether disturbances in emotion regulation precede and predict the emergence of externalizing symptoms; and b) whether sensitive maternal behavior is a significant influence on the development of child emotion regulation. Families experiencing high $(n=58)$ and low $(n=63)$ levels of psychosocial adversity were recruited to the study during pregnancy. Direct observational assessments of child emotion regulation capacities and maternal sensitivity were completed in early infancy, at 12 and 18-months, and at 5-years. Key findings were as follows. First, high risk children showed poorer emotion regulation capacities than their low risk counterparts at every stage of assessment. Second, from 12-months onwards, emotion regulation capacities showed a degree of stability, and were associated with behavioral problems, both concurrently and prospectively. Third, maternal sensitivity was related to child emotion regulation capacities throughout development, with poorer emotion regulation in the high risk group being associated with lower maternal sensitivity. The results are consistent with a causal role for problems in the regulation of negative emotions in the etiology of externalizing psychopathology, and highlight insensitive parenting as a potentially key developmental influence.
\end{abstract}

Keywords: emotion regulation, longitudinal, externalizing disorder, parenting, child development 
The longitudinal development of emotion regulation capacities in children at risk for externalizing disorders

Emotion regulation, broadly conceptualized as the ability to manage states of arousal in order to facilitate adaptive functioning or goal-directed activity, is an essential component of healthy psychological development. Although developmental advances in the ability to regulate emotional responding may continue to into adulthood (Charles \& Carstensen, 2007), the most dramatic gains in emotion regulation capacities occur in the first few years of life. While young infants are almost wholly reliant on their caregiver to regulate their emotional arousal, by 4 or 5 years of age children are already relatively skilled self-regulators, employing multiple strategies to manage their own emotional states (Kopp, 1989; Rothbart, 1989). Normative increases in emotion regulatory capacities appear to contribute to several other development progressions, including decreases in aggression and increases in compliance, and to facilitate effective cognitive and social engagement (Kochanska \& Knaack, 2003; Rothbart \& Derryberry, 1981; Campbell, 2002; Marshall, Fox, \& Henderson, 2002; Eisenberg et al., 1995; Kim \& Cicchetti, 2010).

\section{Emotion regulation and externalizing problems}

Given the contribution of emergent emotion regulation capacities to normal developmental achievements, research attention has turned to the potential role of deficits in the ability to regulate emotions in the etiology of childhood psychopathology (Cole, Michel, \& Teti, 1994; Cicchetti, Ackerman, \& Izard, 1995). Externalizing problems in particular are defined by emotional and behavioral lability, and the underregulation of negative affect is hypothesized to be a causal factor in the etiology of oppositional defiant disorder (ODD) and attention deficit and hyperactivity disorder (ADHD) (Barkley, 1997; Eisenberg, Smith, Sadovsky, \& Spinrad, 2004; Kochanska \& Knaack, 2003; Hinshaw, 2003; Calkins, 1994). Empirical research broadly supports this position. Thus, Cole and colleagues demonstrated concurrent associations between the degree of expression of negative emotion and behavioral 
problems in preschool and early school-aged children (Cole, Zahn-Waxler, \& Smith, 1994; Cole, Zahn-Waxler, Fox, Usher, \& Welsh, 1996). Boys with ADHD have been found to show deficits in emotion regulation, as well as more generalized impairments in regulatory control (Walcott \& Landau, 2004; Melnick \& Hinshaw, 2000). Research has also demonstrated that childhood aggression, particularly reactive aggression, is concurrently associated with impaired regulation of emotional states (Melnick \& Hinshaw, 2000; Shields \& Cicchetti, 1998; Marsee \& Frick, 2007).

While observations of cross-sectional associations between emotional regulation capacities and externalizing psychopathology are important, questions arise regarding the direction of effects. Although emotion regulatory capacities are assumed to represent basic processes that contribute to adjustment, it is also the case that externalizing disorders are themselves characterized by dysregulated affect, and observed emotion regulatory impairments might therefore be symptomatic rather than causal. Longitudinal studies of highrisk populations may speak to this issue, by demonstrating that emotion regulatory deficits precede the emergence of externalizing psychopathology, or predict later psychopathology over and above concurrent symptomatology. However, direct, longitudinal evidence on this point is limited. In a study of disadvantaged boys, the use of particular emotion regulation strategies (distraction, passive waiting, low focus on provocation) at 3.5 years was associated with lower externalizing symptoms at 6-years (Gilliom, Shaw, Beck, Schonberg, \& Lukon, 2002). Kochanska et al. (2003) studied the development of effortful control, a temperament dimension that incorporates the ability to regulate attention, behavioral and also affective states, and reported that better effortful control at 2-3 years predicted lower externalizing symptoms at 6-years child age. Similarly, Eisenberg and colleagues (2005) demonstrated that higher levels of effortful control at 9-years predicted lower levels of externalizing symptoms two years later, even when initial levels of externalizing symptoms were included in the model. Although suggestive, the fact that effortful control indexes behavioral as well as 
emotional regulation means that these studies cannot confirm a specific effect of the latter. Research has also examined the predictive value of physiological indices of regulatory capacities. Longitudinal data from the RIGHT Track Research Project demonstrated that poor vagal regulation of heart rate activity at 2-years of age characterized children with stable behavioral problems through to 4-years (Calkins \& Keane, 2009; Calkins \& Dedmon, 2000; Calkins \& Keane, 2004). Again, these findings are suggestive, as vagal regulation is an assumed physiological concomitant of emotion regulation (Porges, Doussard-Roosevelt, \& Maiti, 1994). However, the urgent need for further longitudinal investigations, and particularly studies that directly examine developing emotion regulation capacities in high risk populations, has been highlighted in the literature (John \& Gross, 2007). Moreover, studies that encompass the first two years of life, assumed to be a key developmental period for emotion regulation capacities (Kopp, 1982), are desirable.

\section{$\underline{\text { Developmental influences on emotion regulation capacities }}$}

Research has also considered the processes that influence the development of good or poor regulatory capacities. Some aspects of regulatory functioning are likely to be determined prior to birth; for example, individual differences in fetal heart rate and movement parameters have been observed which predict relevant aspects of temperament in young infants following birth (Huffman et al., 1998; DiPietro, Hodgson, Costigan, \& Johnson, 1996). Modest genetic influences appear to be present (Goldsmith, Buss, \& Lemery, 1997; DeaterDeckard, Petrill, \& Thompson, 2007), and in-utero factors may also be influential. Smoking during pregnancy has been linked to both emotional and physiological lability in young infants (Fried \& Makin, 1987; Schuetze, Lopez, Granger, \& Eiden, 2008), as well as to externalizing symptomatology (Weitzman, Gortmaker, \& Sobol, 1992; Fergusson, Horwood, \& Lynskey, 1993). Similarly, maternal symptoms of depression and anxiety that occur antenatally, as well as those experienced following birth, have been linked to a profile of disturbances in child development that includes indicators of impaired emotion regulation 
capacities (Blandon, Calkins, Keane, \& O'Brien, 2008; Talge, Neal, \& Glover, 2007; Field, Diego, \& Hernandez-Reif, 2006; Maughan, Cicchetti, Toth, \& Rogosch, 2007; Feng et al., 2008). However, the focus of research to date has been on the role of postnatal and later environmental factors, particularly parenting behaviors.

In early development the regulation of emotional states is conceptualized as being highly dependent on the provision of responsive caregiving behaviors, which assist in the maintenance of an appropriate level of infant arousal (Kopp, 1982; Tronick \& Gianino, 1986; Thompson \& Meyer, 2007; Calkins \& Hill, 2007). Consistent with this position, research has demonstrated that perturbations in maternal responding have an immediate effect on infant arousal, as indicated by changes in behavioral, emotional and physiological state when maternal input is withdrawn during the still face paradigm (Mesman, van IJzendoorn, \& Bakermans-Kranenburg, 2009); and that sensitive parenting post still face may facilitate a quicker return to pre-perturbation state in the infant (Conradt \& Ablow, 2010). More generally, maternal sensitivity appears to facilitate the development of secure attachments, and attachment insecurity is characterized by disturbances in the regulation of emotional responding (Ainsworth, Blehar, Waters, \& Wall, 1978; Cassidy, 1994; Gilliom et al., 2002)

The role of parents also appears to persist beyond early development. Parents may continue to provide input that is concurrently related to child emotional responding through the preschool and early school years, even as children are becoming more adept selfregulators (Cole, Teti, \& Zahn-Waxler, 2003). Moreover, parents are assumed to shape the development of child regulatory capacities such that a persistent influence has been hypothesized (Cole et al., 1994; Thompson, 1994; Calkins \& Hill, 2007; Cassidy, 1994). Broad support for the latter position has been provided. Thus, Calkins and colleagues found that a poorer quality mother-child relationship at 2-years predicted poorer vagal regulation in children at aged 5, even when child behavioral problems and age 2 vagal regulation were controlled for (Calkins, Graziano, Berdan, Keane, \& Degnan, 2008). Similarly, Eisenberg and 
colleagues demonstrated that positive parenting at 9-years predicted adolescent effortful control 2-years later (Eisenberg et al., 2005), even controlling for stability in each of these dimensions and in externalizing symptoms. However, again, while these studies are suggestive of persistent parental influences on child emotion regulation, this question was not specifically addressed. Indeed, although a link between maternal sensitivity and child emotion regulation is widely referred to in the literature, direct, longitudinal evidence on this point is remarkably limited.

Longitudinal data become particularly important when it is considered that parentchild relationships are not exclusively determined by the parent; they also depend, to a degree, on the characteristics that the child brings to dyadic interactions (Patterson, 1995; Cole et al., 2003; Raiha, Lehtonen, Huhtala, Saleva, \& Korvenranta, 2002; O'Connor, DeaterDeckard, Fulker, Rutter, \& Plomin, 1998). Infants who show highly dysregulated emotional responding may have reduced capacity for high quality interactions with their parent. Thus, early indicators of poor regulatory capacity (irritability/negative affect) have been found to predict less optimal maternal behavior in the context of mother-infant interactions (van den Boom \& Hoeksma, 1994; Morrell \& Murray, 2003). However, not all studies have identified equivalent effects (Eisenberg et al., 2005).

\section{The current study}

In sum, existing research highlights a possible role for deficient emotion regulation capacities in contributing to the development of externalizing problems in children; and it identifies insensitive parenting behavior, as well as pre-existing infant characteristics, as potential contributors to regulatory impairments in children. However, to date, longitudinal research examining these putative pathways to child disorder is limited, an omission that raises questions as to the causal direction of observed cross-sectional associations. Moreover, although the first two years of life appear to be critical to the development of emotion regulation capacities, most research has focused on older children. Studies that consider the 
relevance of very early regulatory abilities and parenting behavior to emotion regulation and externalizing problems later in development are particularly lacking. The primary aim of the current study was to examine deficits in early emotion regulation as a potential vulnerability factor for externalizing psychopathology, via a prospective longitudinal study of child emotion regulation capacities that included parent and child observations from the neonatal period. To this end, we studied a sample of 121 mothers and their children, who were recruited to the study during pregnancy and repeatedly assessed from the neonatal period through to childhood (5-years). Approximately half of study families were experiencing high levels of psychosocial adversity (Cronin, Halligan, \& Murray, 2008), defined by the presence of several established risk factors for externalizing disorder, including indicators of socioeconomic deprivation, young maternal age, single parenthood, limited educational qualifications, smoking during pregnancy and symptoms of depression and anxiety (Shaw, Winslow, Owens, \& Hood, 1998; Rutter, Giller, \& Hagell, 1998). In addition to these families at elevated risk for externalizing problems, a low risk comparison group was also studied. The resultant groups provided, therefore, a context in which to test the hypothesis that poor emotion regulation capacities distinguish high risk children from an early age, and precede and predict the emergence of externalizing symptoms.

A second major aim was to test the hypothesis that parenting behavior, particularly maternal insensitivity, is longitudinally associated with poorer emotion regulation capacities in children, and thereby contributes to the development of externalizing behaviors. We also tested for the converse association, i.e., infant behaviors preceding and predicting the development of insensitive maternal behavior. In order to avoid the problems associated with basing multiple assessments on maternal report or the confound of examining both maternal and child characteristics in the same assessments, indices of child emotion regulation and maternal behavior were derived from independent observational assessments. 
Our high versus low psychosocial adversity groups were recruited first and foremost as a context for studying risk for externalizing problems (Shaw, Gilliom, Ingoldsby, \& Nagin, 2003; Shaw et al., 1998). Recruitment ensured that multiple difficulties co-occurred in our high psychosocial adversity sample, and the sample overall was relatively small.

Consequently, our study was not suitable for a comprehensive analysis of the relevance of specific adversities. Nonetheless, in secondary analyses we examined the possibility of specific contributions to child emotion regulation for a subset of theoretically indicated dimensions. We obtained robust assessments of maternal smoking and affective symptoms in the current study, and were therefore able to conduct exploratory analyses examining possible direct influences on the development of emotion regulation. Maternal age was also subject to similar, exploratory investigation. Although observed associations between maternal age and child behavior problems appear to be largely explained by less optimal parenting practices and home environments (Fergusson \& Lynskey, 1993; Fergusson \& Woodward, 1999), there may also be specific relevant characteristics of mothers who become pregnant at a relatively young age that have effects that are independent of parenting (e.g., poor self care during pregnancy) (Woodward, Horwood, \& Fergusson, 2001). Finally, maternal and child cognitive abilities distinguished our high versus low risk groups. In this case, the interpretation of a possible link to developing emotion regulation capacities is complex, as theoretical accounts have tended to assume that cognitive and emotional control are underpinned by similar systems, or exert mutual developmental influences on each other (e.g., Kochanska \& Knaack, 2003; Rothbart \& Derryberry, 1981). Nonetheless, a preliminary examination of whether risk group differences in emotion regulation were related to cognitive abilities was conducted.

Methods

Sample

Primiparous mothers attending their routine 20 -week antenatal scan appointment at the Royal Berkshire Maternity Hospital in Reading, UK, were screened via a 20 item 
questionnaire indexing multiple indicators of psycho-social adversity, specifically: young maternal age, single parenthood/relationship instability, limited qualifications, unemployment, low income/resources, unstable/unsatisfactory living conditions, smoking during pregnancy, and feelings of depression and anxiety. Questionnaire completion was rate 72.5\% (see Cronin et al., 2008). Of 198 women initially contacted based on their questionnaire scores, 67 mothers scoring above a cut off defining the $20 \%$ highest scores (high risk group) were recruited to the study, along with 68 mothers with scores in the $40 \%$ lowest scoring range (low risk group). High versus low risk women did not differ in terms of recruitment percentages (high risk $64 \%$, low risk $60 \%: \chi^{2}=0.56, \mathrm{df}=1, \mathrm{~ns}$ ). After excluding those delivering prematurely or withdrawing from the study prior to delivery, numbers in high and low risk groups were 58 and 63 respectively.

On the questionnaire's principal demographic indices of adversity, compared to the low risk group, high risk women were younger [high risk $M=19.7, S D=3.3$; low risk $M=$ $30.6, S D=3.3$ years; $t_{120},=18.3, P<0.001$ ], more often single [high risk $53.4 \%$, low risk $0 \% ; \chi^{2}(1)=45.9, P<0.001$ ], and unemployed [high risk $63.2 \%$, low risk $3.1 \% ; \chi^{2}(1)=50.4$, $P<0.001$ ] , and fewer were educated beyond 16 years [high risk $14.8 \%$, low risk $96.8 \% ; \chi^{2}$ $(1)=80.8, P<0.001]$. The sample was $86 \%$ Caucasian, with ethnic minorities being better represented in the high risk group (high risk $21 \%$, low risk $8 \%: \chi^{2}=4.23$, $\mathrm{df}=1, P=0.04$ ). Groups were similar in terms of infant characteristics including gender (both groups 52\% female), gestational age (high risk $M=280.2$ days, $S D=10.0$; low risk $M=279.6, S D=$ 10.4), and 1 minute Apgar scores (for both groups, median = 9, range =7); but the high risk group had lower birth weights (high risk $M=3.30 \mathrm{Kg}, S D=0.57$; low risk $M=3.51 \mathrm{Kg}, S D=$ $\left.0.50 ; t_{120}=2.09, P<0.05\right)$. Of the original 121 families who completed the first stage of assessments (28-weeks gestation through to 12-weeks postpartum), 105 completed the second stage of assessments (12 and/or 18-months), and 98 completed the final 5-year assessments. 


\section{Assessments}

Measures used in the current study derived from assessments completed at 28 and 34weeks gestation, in the neonatal period (10-days, 4-weeks, 12-weeks infant age), at 12- and 18-months, and in childhood (5-years). Specifically, child emotion regulation was measured at 10-days and 4-weeks, 12- and 18-months, and at 5-years; and maternal sensitivity was measured at 12-weeks, 12 and 18-months, and at 5-years. Where identical assessments were completed across proximal time points, average scores were used for analyses. This applied to the assessment of emotion regulation utilized at 10-days and 4-weeks; and to both infant and maternal assessments completed at 12- and 18-months ${ }^{1}$. This approach was adopted in order to limit the number of analyses run in our relatively small sample, to provide robust indices of the dimensions measured, and also to minimize the impact of missing data points. Neonatal and 12/18-month data refer to these combined scores hereafter.

\section{$\underline{\text { Background Information }}$}

Initial demographic information was collected via the screening questionnaire (Cronin et al., 2008). Smoking during pregnancy was reported by mothers and validated via salivary Cotinine tests. Infant birth weight was ascertained via hospital delivery records.

\section{$\underline{\text { Maternal affective symptoms }}$}

Mothers completed the Hospital Anxiety and Depression Scale (HADS) (Zigmond \& Snaith, 1983) at 28-weeks/34-weeks gestation (averaged as an 'antenatal' score for analyses), and at 12/18-months and 5-years child age. The HADS is a brief instrument which yields reliable and valid measures of the symptoms of depression and anxiety (in the current student Chronbach's $\alpha$ ranged from .82 to .86 ). Mothers also completed the Edinburgh Postnatal Depression Scale (EPDS) (Cox, Holden, \& Sagovsky, 1987) at 4-weeks postpartum, a self-

\footnotetext{
${ }^{1}$ We did not have differential predictions relating to the intervening data, and did not aim to examine developmental changes in relevant dimensions per se; therefore this approach did not undermine our research questions. Correlations between key equivalent dimensions were all moderate and significant (neonatal selfregulation $r=.36 ; 12 / 18$-months BSQ $r=.45$, emotion regulation $r=.44$, maternal sensitivity $r=.44$ ); and the pattern of results was essentially the same for individual time points versus combined assessments.
} 
report scale that has been specifically developed to measure depressive symptoms as they occur in the postnatal context $(\alpha=.82)$.

\section{$\underline{\text { Child emotion regulation }}$}

Emotion regulation was assessed neonatally, at 12/18-months and 5-years child age using age-appropriate observational measures.

Neonatal Assessments: The Neonatal Behavior Assessment Scale (NBAS) (Brazelton \& Nugent, 1995) is a well-established observational assessment of a range of neonatal behaviors and reflexes that are clustered into meaningful dimensions; it was administered by trained researchers in the infants' own homes at 10-days and 4-weeks postpartum. The state regulation cluster (comprising the dimensions of 'cuddliness', 'consolability', 'self-quieting' and 'hand-to-mouth') predominantly refers to regulation of emotional state and is referred to, for simplicity, as a measure of neonatal emotion regulation in the present study. Scores in the current study showed acceptable reliability (Chronbach's $\alpha=.66$ ), and were combined across 10-day and 4-week assessments.

12/18-month Assessments: Emotion regulation capacities were indexed via two assessments. First, the Bayley Scales of Infant Development - Second Edition (BSID-II) (Bayley, 1993) were administered in the laboratory by a trained researcher. The BSID-II is a standardized assessment of infant abilities which is widely used as a research tool. The BSIDII includes the Emotion Regulation Scale (ERS), an observer rating scale which is based on infant behavior throughout the administration of the test battery. Infant behavior is rated on multiple dimensions, which index the occurrence of dysregulated behaviors, response to changing demands, proneness to negative affect, sensitivity to test materials, and task persistence. The ERS has established reliability and validity (in the current study $\alpha=.87$ ).

Second, two of the four 'Anger Episodes' from the Locomotor Lab-TAB (Goldsmith \& Rothbart, 1999) were administered. Infants completed 3 trials where an attractive toy was taken from them and placed behind a clear Perspex barrier for 30-seconds, immediately 
followed by 2 trials in which the mother gently restrained the infant's arms for 30-seconds to prevent them from reaching a toy. Episodes were filmed and subsequently coded by two raters blind to status, using The Observer 4.1 (Noldus software). The elapsed time until the first expression of frustration on each trial was coded (as indexed by back arching, struggling and crying) and average latency to frustration across trials computed $(\alpha=.77)$.

A single index of emotion regulation capacities was computed based on the above two measures, which were positively correlated with each other $(r=0.42, P<0.001)$. In combination, these two scales capture both behavioral aspects of emotion regulation (i.e., the extent to which regulatory versus dysregulatory behaviors occur), and the extent to which negative emotion is effectively contained (as evidenced by the latency to frustration across increasingly provocative episodes). Due to the different measurement scales, ERS and LabTAB latency to frustration scores were both transformed into standardized scores to ensure that they contributed equal weight; the composite comprised the mean of the standardized scores. Average scores across 12-month and 18-month assessments were utilized.

5-year Assessment: At 5-years we developed a novel 'buzz wire' assessment, whereby children attempted to move a hoop along a wire without touching the wire, which caused the apparatus to buzz. Task difficulty was such that all children touched the wire. Children were instructed that if they buzzed too many times then a red light would come on, requiring them to restart the task. Children were given 3x1-minute attempts to complete the task and win a prize. The task was rigged such that the red light was controlled by the experimenter and was activated 4 times per trial regardless of child performance. As such, all children were unable to complete the task within the pre-specified 3 trials. Pilot work established that this task routinely elicited transient expressions of negative affect in children.

Assessments were video recorded subsequently coded. Scores for the task were derived from latency to the expression of negative affect in each trial and the frequency of emotion regulation strategies. Negative affect was indicated by affective verbalizations and 
behaviors, crying, or disengaging from the task. Self-regulatory behaviors were coded based on procedures specified by Cole and colleagues (Cole, Wiggins, Radzioch, \& Pearl, 2007), including: child-initiated bids to engage the experimenter (excluding negative emotional expressions), self-soothing behaviors, self-directed verbalization, attempts to modify behavior to 'fix' the situation (e.g., testing a new strategy), and focusing attention on the demand. Children showed a significant reduction in the latency to negative affect from trial to trial, with means of $47.4 \mathrm{~s}$ in trial $1,30.5 \mathrm{~s}$ in trial 2, and 22.7s in trial 3; and also significant increases in the use of emotion regulation strategies from trial $1(M=4.0)$, to trials 2 and 3 $(M=5.1$ and $M=4.7)$. An index of emotion regulation was derived for the task based on the combined, standardized scores for mean latency to negative emotion and total regulatory strategies utilized $(\alpha=.68){ }^{2}$

\section{Maternal parenting behavior}

Mothers completed interactions with their child at 12-weeks, 12-months, 18-months and 51/2-years post-partum. All interactions were video recorded and subsequently coded for maternal sensitivity. At 12-weeks, mothers played face-to-face with their infants in their homes for a five-minute period. Maternal sensitivity (warm, responsive, accepting behavior that takes appropriate account of infant cues) was scored on a series of standard five-point rating scales (Murray, FioriCowley, Hooper, \& Cooper, 1996). The rating scheme has previously been used to distinguish a number of different maternal and infant conditions (Gunning et al., 2004), including the effects of psychosocial adversity (Murray et al., 1996). At 12/18-months mothers and infants were recorded in the course of face-to-face play based on three 2.5-minute consecutive sessions with a series of toys (Wolke, Skuse, \& Mathisen,

\footnotetext{
${ }^{2}$ Given the novelty of the 5-year emotion regulation assessment, factor analysis was used to examine the construct validity of the regulatory scales. A principal components analysis was applied to task scores. The scree plot was consistent with a 2 factor solution. All items loaded positively on the first factor extracted scale (item loadings range 0.10 to 0.65 ), consistent with our assumption that we were indexing a single regulatory dimension. The second factor that emerged could be explained as representing a primarily verbal versus physical strategy regulatory dimension. Additional factors were not readily interpretable. As we had no hypotheses about the significance of verbal versus physical regulatory strategies, this differentiation was not considered further.
} 
1990). Maternal sensitivity to the infant was again rated on 5-point scales for each of the three segments and an average score for the interaction computed. At 5-years, mothers and children completed an interaction comprising 10-minutes of free play with a desirable set of toys (PlayDoh), followed by 5-minutes of play with an age inappropriate toy (shape sorter) and a tidy-up of all toys (Dadds, Mullins, McAllister, \& Atkinson, 2003; Gardner, SonugaBarke, \& Sayal, 1999). Maternal sensitivity was scored for each segment of the interaction, on 5-point rating scales equivalent to those employed at previous assessments, adapted to be age-appropriate. Average scores for the interaction were computed.

\section{Child behavioral problems}

At 12/18-months mothers completed an age-adapted version of the Behavior Screening Questionnaire (Richman \& Graham, 1971), in semi-structured interview format. The BSQ was originally developed as a screen to identify a range of clinical problems in 3year-old children. Items address a range of common childhood problems. The version used in the current study comprised a reduced set of 8 -items which has previously been found to be appropriate for the study age range (Murray, 1992; Ghodsian, Zajicek, \& Wolkind, 1984). We analyzed scores for items specifically addressing externalizing-type difficulties (temper tantrums and hard-to-manage behaviors). The scale has previously been shown to have good external validity and acceptable reliability (Ghodsian et al., 1984; Richman \& Graham, 1971). Reliability for the externalizing scale used in the current study was acceptable $(\alpha=$ $.78)$.

At 5-years both mothers and teachers completed the Strengths and Difficulties Questionnaire (SDQ) (Goodman, 1997; Goodman, Ford, Simmons, Gatward, \& Meltzer, 2000), a broad measure of child functioning with subscales covering attention/hyperactivity problems, conduct problems, emotional problems, peer problems and prosocial behavior. Externalizing subscales (conduct/hyperactivity) were the primary outcome in the current study. The SDQ is a standardized, widely used assessment which has excellent reliability and 
validity. Maternal and teacher report scores were significantly correlated $(r=0.53)$ and were combined for analytic purposes (overall reliability $\alpha=.88$; in all cases, maternal and teacher scores showed the same pattern of results).

\section{$\underline{\text { Cognitive abilities }}$}

At 12/18-months, infants completed the BSID-II, as already described. In addition to the use of the emotion regulation scale, the Mental Development Index was utilized as an index of cognitive abilities. At 5-years, subscales of the Wechsler Preschool and Primary Scale of Intelligence - Revised (WPPSI-R, Wechsler, 1991) were administered. The WPPSI$\mathrm{R}$ is a reliable and valid assessment of intelligence in children aged from three years to seven years, and yields indices of performance and verbal IQ, which in combination provide a full IQ score (in the current study $\alpha=.83$ ). In addition, the National Adult Reading Test (NART; (Nelson \& Willison, 1991) was administered to mothers at the 5-year assessment. The NART is based on reading irregular English words, and yields scores that are highly correlated with standard IQ tests (Bright, Jaldow, \& Kopelman, 2002).

\section{Coding and Reliability}

Coding was completed by trained raters who were blind to maternal group status. Coding reliability was established in two ways. For assessments where coding occurred online (NBAS, Bayley Scales), researchers were pre-trained to an acceptable level of reliability in the course of the standard training procedures. For ratings made on videorecordings a minimum $10 \%$ of the sample was double scored. Intraclass correlations ranged from $r=0.76$ (maternal sensitivity at 5-years) to $r=0.94$ (regulatory behaviors on the 5-year buzz wire task).

Statistical analyses

Since infant birth weight and ethnicity differentiated the adversity groups, they were screened as potential covariates in relation to the key outcomes of child emotion regulation capacities and externalizing symptoms; neither was related to these outcomes and therefore 
they were not considered further. Several other demographic characteristics differentiated the groups, as already described, but these were part of the selection process for high versus low adversity groups and therefore could not logically be considered as confounds in relation to group status. Psychosocial adversity group comparisons of child characteristics and maternal parenting behavior were carried out using multivariate analysis of variance (MANOVA) for parametric variables and Mann-Whitney U tests for non-parametric variables (12/18-month BSQ scores). Child gender was taken into account throughout. Associations between child emotion regulation scores and behavioral problem scores were first examined using bivariate correlations; and for 5-year outcomes, regression analyses further investigated whether emotion regulation scores could predict externalizing symptoms once adversity status, child gender and previous behavioral problem scores were taken account of. Bivariate correlations also tested for concurrent and prospective associations between maternal behavior and child emotion regulation. Longitudinal pathways from adversity status to child outcomes, via intervening child emotion regulation capacities and maternal behavior were then examined using path analysis, conducted using Maximum Likelihood Estimation with the MPLUS 4.2 software (Muthen \& Muthen, 2007). The Satorra-Bentler scaled difference chi-square significance was used for model comparisons (Satorra \& Bentler, 2001). Finally, exploratory correlations tested whether child emotion regulation scores were specifically predicted by maternal age, antenatal smoking, antenatal and subsequent maternal affective symptoms, or maternal/child cognitive abilities (see group differences in Table 1); and follow up regression analyses examined whether identified associations still held once overall risk group status was taken into account.

Missing data: As noted, the sample reduced from 121 at recruitment to 98 at 5-year follow-up ( $81 \%$ retention rate). There was more attrition from the high versus the low-risk 
group $\left(17 / 58 \text { versus } 6 / 63 \text { at } 5 \text {-years; } \chi^{2}=7.68, \mathrm{df}=1, P=0.006\right)^{3}$. Therefore, we further examined whether those who dropped out were comparable to those in their group on the screening questionnaire and all available study outcomes. ANOVAs comparing scores by retention status while controlling for risk group indicated no significant differences by retention status on any measure; and effect sizes for comparisons on relevant variables were all small (partial $\eta^{2}$ ranged <.001 to .02). Within group comparisons by retention status yielded similar results. Thus, participants who were retained in the study appeared representative of those originally recruited to their group. Moreover, path analyses were based on the entire recruitment sample (i.e., $n=121$ ) with missing data modelled using full information maximum likelihood estimation, the recommended approach for minimizing the introduction of bias due to missing data (Schafer \& Graham, 2002; Allison, 2003).

\section{Results}

\section{Child adjustment}

An initial set of group comparisons examined child adjustment in relation to adversity status (see Table 1 for descriptive statistics). With respect to BSQ scores at 12/18-months, non-parametric analyses indicated that relative to their low risk counterparts, high risk children showed more behavioral problems $(Z=-3.43, P=0.001)$. Scores were similar for boys and girls $(Z=-0.09, \mathrm{~ns})$. When ANOVA was used to examine 5-year externalizing symptoms (SDQ) in relation to risk status and gender, the results indicated a significant effect of risk status $\left(F_{1,94}=8.23, P=0.005\right.$, Partial $\left.\eta^{2}=0.08\right)$, reflecting higher scores for the high versus low risk group (Table 1), a trend for an effect of gender (boys $M=6.8, S D=3.6$; girls $M=5.2, S D=4.4 ; F_{1,94}=5.2, P=0.054$, Partial $\left.\eta^{2}=0.04\right)$, but no risk by gender interaction $\left(F_{1,94}=0.06, \mathrm{~ns}\right)$

\section{Emotion regulation capacities and the emergence of externalizing behaviors}

\footnotetext{
${ }^{3}$ Rates of refusal were similar across groups ( 3 high versus 2 low risk mothers at 5 -years), but a higher proportion of the high risk families could not be traced (14 high-risk versus 4 low-risk mothers at 5-years).
} 
In order to test the hypothesis that risk status would be associated with impaired child emotion regulation capacities, MANOVA was used to examine child emotion regulation scores in the neonatal period, at 12/18-months and at 5-years in relation to the independent variables of risk status and child gender. Multivariate tests indicated a main effect of risk status on emotion regulation scores (Pillai's Trace $F_{3,89}=6.86, P<0.001$, Partial $\eta^{2}=0.19$ ). Follow-up univariate tests indicated that this was due to significantly lower scores in the high versus low risk groups at $12 / 18$-months $\left(F_{1,91}=8.26, P=0.005\right.$, Partial $\left.\eta^{2}=0.08\right)$ and at 5 years $\left(F_{1,91}=10.66, P=0.002\right.$, Partial $\left.\eta^{2}=0.11\right)$, with a trend for the same effect in the neonatal period $\left(F_{1,91}=3.75, P=0.056\right.$, Partial $\left.\eta^{2}=0.04\right)$ (see Table 1 for descriptive statistics; note that the trend for a group difference neonatally was significant when all 121 cases available for this assessment point were analyzed, $t_{121}=2.06 . P=0.042$ ). Multivariate tests also indicated a significant gender effect (Pillai's Trace $F_{3,89}=6.55, P<0.001$, Partial $\eta^{2}=0.18$ ), which univariate tests revealed was due to boys having lower regulatory scores than girls at 5-years (boys $M=-0.31, S D=0.67$; girls $M=0.32, S D=0.76 ; F_{1,91}=19.0, P<$ 0.001 , Partial $\eta^{2}=0.17$ ), but not at $12 / 18$-months or at the neonatal assessment. There was no risk by gender interaction (Pillai's Trace $F_{3,89}=0.79$, ns).

We next tested the hypothesis that poorer emotion regulation capacities would be associated with the emergence of child problem behaviors. Correlations are presented in Table 2. Neonatal emotion regulation scores showed no associations with later behavioral problems, and there was also no stability from neonatal to subsequent emotion regulation. However, 12/18-month emotion regulation scores were significantly negatively correlated with concurrent behavioral problem scores and with 5-year externalizing symptoms; and 5year emotion regulation scores were also negatively correlated with concurrent externalizing difficulties. Furthermore, emotion regulation capacities showed moderate stability over the same period (12- to 18-months $r=0.41, P<0.001 ; 18$-months to 5-yrs $r=0.35, P=0.001$ ). 
Positive associations observed between emotion regulation capacities and externalizing symptoms were examined further. Specifically, linear regression investigated the extent to which emotion regulation variables could predict child externalizing difficulties at 5-years once earlier behavioral problems (12/18-month BSQ scores), child gender and risk group status were taken into account. Child gender, BSQ scores, and risk status were entered into the model in the first $\operatorname{step}\left(R^{2}=0.12, F_{3,91}=4.14, P=0.008\right)$. The addition of $12 / 18$ month emotion regulation scores in the second step significantly improved model fit $\left(\Delta R^{2}=\right.$ $\left.0.06, \Delta F_{1,90}=6.24, P=0.014\right)$, as did 5-year emotion regulation scores in a third step $\left(\Delta R^{2}=\right.$ $\left.0.09, \Delta F_{1,89}=10.5, P=0.002\right)$. The final model was highly significant $\left(F_{5,89}=6.38, P<\right.$ 0.001 ), accounting for $26 \%$ of the variance in child externalizing symptoms; notably, emotion regulation as measured at $12 / 18$-months $(B=-1.01, S E=0.46, \beta=-0.22, P=0.031)$ and at 5years $(B=-1.44, S E=0.45, \beta=-0.35, P=0.002)$ were the only independently significant predictors of externalizing symptoms in the final model.

Finally, we examined the specificity of associations between emotion regulation capacities and child externalizing versus internalizing difficulties. Basic correlations examined associations between emotion regulation capacities and child internalizing problems, as indexed by 5-year emotional problem scores on the SDQ. In contrast to the moderate to large effects reported for child externalizing symptoms, results indicated that emotional problem scores were not significantly related to either $12 / 18$-month or 5-year emotion regulation scores (12/18-month $r=-0.14$, ns; 5-year $r=-0.18, P=0.075)$; and at 5years the difference in magnitude of correlations for externalizing versus internalizing symptoms with emotion regulation capacities was significant $\left(12 / 18\right.$-month $t_{95}=1.55$, ns; 5 year $\left.t_{95}=2.29, P=0.02\right)$.

\section{The role of maternal parenting behavior}

We investigated the role of maternal sensitivity in: a) differentiating high and low risk groups; b) predicting the development of child emotion regulation capacities; and c) thereby 
contributing to the emergence of externalizing symptoms. First, MANOVA was used to examine the prediction of maternal sensitivity at 12-weeks, 12/18-months and 5-years by risk status and child gender (descriptive statistics in Table 1). The results indicated an overall effect of risk status (Pillai's Trace $F_{3,84}=16.0, P<0.001$, partial $\eta^{2}=0.36$ ), which reflected lower sensitivity in the high versus low risk group at every assessment point: neonatal $F_{1,86}=$ 15.9, $P<0.001$, partial $\eta^{2}=0.16 ; 12 / 18$-month $F_{1,86}=21.5, P<0.001$, partial $\eta^{2}=0.20 ; 5$ year $F_{1,86}=28.0, P<0.001$, partial $\eta^{2}=0.25$. There was also a multivariate effect of child gender (Pillai's Trace $F_{3,84}=2.95, P=0.037$, partial $\eta^{2}=0.10$ ), which reflected lower sensitivity in relation to boys $(M=3.2, S D=0.66)$ versus girls $(M=3.5, S D=0.54)$ at $12 / 18$ months only. There was no gender by risk interaction (Pillai's Trace $F_{3,84}=0.06$, ns).

Second, concurrent and prospective associations between maternal sensitivity and child emotion regulation capacities were examined. Specifically, we investigated whether maternal sensitivity was associated with concurrent child regulation, and could predict child emotion regulation capacities at the next assessment point. As can be seen from the full intercorrelation presented matrix in Table 2, higher maternal sensitivity was associated with higher concurrent and subsequent child emotion regulation at each assessment from 12-weeks through to 5-years. Conversely, we also tested whether child emotion regulation could predict maternal sensitivity at the next time point. Neonatal emotion regulation (10-days/4-weeks) was not found to be a significant predictor of subsequent maternal sensitivity at 12-weeks. However, better regulated 12/18-month olds had mothers who were more sensitive at 5-years (see Table 2).

Third, indirect pathways from earlier maternal sensitivity to 5-year externalizing symptoms via emotion regulation were examined (Preacher \& Hayes, 2008). For 12-week sensitivity, results indicated a significant indirect pathway to 5-year SDQ scores via emotion regulation in infancy and at 5-years (bootstrapped total indirect effect $=-0.73,95 \% \mathrm{CI}=$ 1.33 to $-0.34, P=0.010$; infancy indirect effect $=-0.30, \mathrm{CI}=-0.76$ to $-0.10 ; 5$-year $=-0.43$, 
$C I=-0.96$ to -0.13$)$. Similarly, for infancy maternal sensitivity, results indicated a significant indirect pathway to 5-year SDQ scores via emotion regulation in infancy and at 5-years (bootstrapped total indirect effect $=-0.75,95 \% \mathrm{CI}=-1.42$ to $-0.32, P=0.007$; infancy indirect effect $=-0.26, \mathrm{CI}=-0.64$ to $-0.06 ; 5$-year $=-0.49, \mathrm{CI}=-1.06$ to -0.15$)$.

\section{$\underline{\text { Multivariate analyses }}$}

Based on the outcomes of the above analyses, we examined longitudinal pathways to child outcomes via path analysis. Two related models were constructed: the first focused on child emotion regulation as the primary outcome, and the second additionally considered pathways to child externalizing symptoms. A preliminary analysis in relation to child emotion regulation capacities, based on positive findings established in the preceding sets of analyses, examined sequential paths from risk status to 5-year emotion regulation via both intervening emotion regulation (excluding the neonatal index, which was unrelated to subsequent outcomes) and maternal behavior. The model fit was $\operatorname{poor}^{4}\left(\chi^{2}=27.1, \mathrm{df}=5, P<\right.$ $0.001 ; \mathrm{CFI}=0.79, \mathrm{TLI}=0.38 ; \mathrm{RMSEA}=0.19,90 \% \mathrm{CI}=0.13-0.27)$ and the covariance matrix indicated strong associations between risk status and maternal behavior at every stage of assessment. These additional direct risk-parenting pathways were included and three pathways with $\mathrm{P}>0.10$ (dashed lines in Figure 1) were dropped. The resultant model (Figure 1), showed a good fit $\left(\chi^{2}=6.87, \mathrm{df}=6, P=0.33 ; \mathrm{CFI}=0.99, \mathrm{TLI}=0.98 ; \mathrm{RMSEA}=0.04\right.$, $90 \% \mathrm{CI}=0-0.13)$. As can be seen from the figure, risk status influenced 5-year emotion regulation both via intervening emotion regulation and maternal parenting behavior. Parenting behavior showed a degree of stability over time, but was also strongly influenced by psychosocial risk at every time point. The addition of a further direct pathway from risk status to 5-year emotion regulation did not result in a better fitting model (Satorra-Bentler scaled chi-square difference test $\left.\chi^{2}=1.69, \mathrm{df}=1, \mathrm{~ns}\right)$, and this pathway was not significant

\footnotetext{
${ }^{4}$ For the Comparative Fit Index (CFI) and Tucker Lewis Index (TLI) values of 0.90 or above indicate acceptable fit. For the Root Mean Square Error of Approximation (RMSEA) values of less than .08 indicate a reasonable model fit.
} 
(standardized coefficient $=-0.14, Z=-1.30)$. In sum, path analysis supported the conclusion that maternal sensitivity was a significant influence on developing child emotion regulation capacities, and contributed to the association between risk status and poorer emotion regulation. Reverse effects, from child emotion regulation to later maternal sensitivity (demonstrated in basic correlations from 12/18-months to 5-years) were not significant.

A second set of models additionally examined prediction of child externalizing scores on the SDQ. A preliminary analysis included a full set of possible concurrent and prospective associations from parenting and emotion regulation variables to SDQ scores. Two of these direct pathways - from 12/18-month emotion regulation and 12/18-month maternal sensitivity - had $P$ values $>.10$ and were dropped from the model. The resultant model showed a good fit $\left(\chi^{2}=10.73, \mathrm{df}=9, P=0.29 ; \mathrm{CFI}=0.99, \mathrm{TLI}=0.97 ; \mathrm{RMSEA}=0.04,90 \% \mathrm{CI}=0-0.12\right)$. As can be seen from Figure 2, 5 year externalizing symptoms on the SDQ were independently predicted by maternal parenting behavior (both concurrently and longitudinally) and by child emotion regulation capacities.

Building on this model, we examined the impact of including earlier child difficulties (i.e., BSQ scores at 12/18 months) on existing pathways to 5-year externalizing problems; and also tested whether earlier problem behaviors predicted later emotion regulation and maternal sensitivity. A preliminary model included a full set of possible concurrent and prospective associations from parenting and emotion regulation variables to BSQ scores, as well as a pathway from BSQ to SDQ scores. Only two significant pathways were identified, to $12 / 18$-month BSQ scores from both risk status $(\beta=.29)$ and $12 / 18$ month emotion regulation $(\beta=-.27)$. Although the pathway from BSQ scores to SDQ scores was nonsignificant $(\beta=.04)$, it was retained as we particularly wanted to take account of longitudinal stability in behavioral problems. All other pathways were dropped. The resultant model showed a good fit $\left(\chi^{2}=11.60, \mathrm{df}=13, P=0.56 ; \mathrm{CFI}=1.00, \mathrm{TLI}=1.02 ; \mathrm{RMSEA}=0.01\right.$, $90 \% \mathrm{CI}=0-0.08)$, but the existing pathways identified in Figure 2 were essentially 
Running Head: Emotion regulation and risk for externalizing disorder

unchanged (model not depicted). Further analysis examined the impact of adding: a) a direct pathway from risk status to 5-year externalizing symptoms; and b) forward pathways from BSQ scores to 5-year emotion regulation and maternal sensitivity. All of these additional pathways were non-significant (standardized coefficients ranged -.03 to -.09, maximum $Z=-$ 0.82); and there was also no significant change in model fit (Satorra-Bentler scaled chi-square difference test $\chi^{2}=0.96, \mathrm{df}=3, \mathrm{~ns}$ ). Thus, links between emotion regulation, parenting and SDQ scores did not appear to be accounted for by earlier behavioral problems; and the association between risk status and levels of externalizing symptoms was explained, at least in part, by disturbances in emotion regulation capacities and maternal insensitivity.

\section{Proximal components of risk}

We conducted exploratory analyses of key proximal influences on fetal and child development: maternal age, affective symptoms (measured at each assessment point), and Cotinine validated smoking during pregnancy. Smoking during pregnancy essentially occurred exclusively in the high risk (35/58) versus low risk (1/63) group. Thus, although antenatal smoking was associated with poorer emotion regulation at $12 / 18$-months $(P=$ 0.019), when the presence/absence of smoking was considered just within the high risk group there was no evidence for an effect $(P>0.4)$; and no effect of smoking emerged at other time points $(P \mathrm{~s}>0.19)$. Bivariate correlations for maternal age and affective symptoms are reported in Table 3. Higher maternal affective symptoms relatively consistently predicted poorer child emotion regulation capacities, including prospective associations from antenatal HADS scores. Younger maternal age also predicted poorer emotion regulation capacities at 12/18-months and 5-years.

Regression analyses examined whether any of the significant effects of maternal age and affective symptoms could predict child emotion regulation outcomes independently, over and above overall risk effects. For the prediction of neonatal emotion regulation, antenatal and postnatal maternal affective symptoms were tested, and significantly improved model fit 
$\left(\Delta R^{2}=0.07, \Delta F_{2,117}=4.40, P=0.014\right)$, over and above risk status alone $\left(R^{2}=0.03, F_{1,118}=\right.$ $3.98, P=0.048)$. Postnatal EPDS scores were the only significant, independent predictor in the resultant model $(\beta=-0.22, t=-2.32, P=0.022)$. For the prediction of $12 / 18$-month emotion regulation and 5-year emotion regulation, maternal age and mental health variables did not contribute additional variance over and above risk status alone, and the resultant models contained no independently significant predictors.

Finally, given assumed interplay between cognitive and emotional development, and the existence of IQ differences between our two groups (see Table 1), we examined child IQ as a covariate for analyses. Preliminary analyses revealed significant correlations between emotion regulation at 12/18 months and the Mental Development Index of the BSID-II, completed at the same time points $(r=0.50, \mathrm{n}=109, P<0.001)^{5}$; and between IQ as measured by the WPSSI-R at 5-years and 5-year emotion regulation $(r=0.24, \mathrm{n}=97, P=$ 0.016). Maternal IQ at 5-years as indexed by the NART was unrelated to child emotion regulation $(r=0.15, n s)$. Further linear regression analyses showed that associations between risk status and emotion regulation were maintained once cognitive abilities were also included in the model at both $12 / 18$-months (risk $\beta=-0.20, t=-2.40, P=0.018$; mental index $\beta=-0.46, t=5.55, P<0.001)$ and 5-years (risk $\beta=-0.25, t=-2.18, P=0.032$; IQ $\beta=-0.11, t$ $=1.04, n s)$.

\section{Discussion}

The key findings from the current study were as follows. First, risk for externalizing psychopathology, conferred by virtue of maternal psychosocial adversity, was associated with poorer emotion regulation capacities from the neonatal period through to 5-years child age. Moreover, child emotion regulation capacities showed a degree of stability from the start of the second year of life through to 5-years, and were associated with emergent child

\footnotetext{
${ }^{5}$ Note that measures of emotion regulation partially derived from the emotion regulatory scales of the BSID-II for 12/18-month assessments. The common assessment with the mental index is likely to have contributed to the particularly high correlation in this case.
} 
externalizing difficulties over the same period (neonatal regulation was neither stable nor associated with later behavioral problems). A degree of specificity in the emotion regulation/externalizing symptoms association was tentatively indicated, since equivalent effects were not apparent in relation to internalizing symptoms. Second, psychosocial adversity was also associated with less sensitive maternal parenting behavior from the neonatal period through to five years. This association was pervasive: thus, adversity continued to be linked to less optimal parenting at later assessments, even once associations with earlier parenting were taken into account. Finally, there were interrelationships between maternal parenting and child outcomes throughout development, which contributed to associations between psychosocial adversity and both poorer emotion regulation and higher levels of externalizing symptoms.

The current findings highlight the presence of impairments in the ability to regulate negative emotional states that characterize at-risk children, even from relatively early in development, and that are longitudinally associated with externalizing symptomatology. Consistent with our observations, previous research has reported longitudinal associations between effortful control and externalizing symptoms, in studies spanning both early to middle childhood (Kochanska \& Knaack, 2003) and early adolescence (Eisenberg et al., 2005). However, whereas effortful control incorporates multiple aspects of self-regulation, our study indicates that emotion regulation capacities in particular may be a significant factor in predicting child externalizing difficulties. Moreover, emotion regulation capacities measured as early as 1 year child age had the capacity to predict subsequent externalizing symptoms through to 5-years in the current study, even once concurrent behavioral problems were controlled for. Overall, our longitudinal findings provide important support for the proposal that emotion regulation deficits contribute to the development of externalizing disorders, and are not merely symptomatic of pre-existing externalizing problems. Nonetheless, our data are correlational, precluding strong conclusions regarding causality. 
Thus, in path analyses the association between early emotion regulation capacities and 5-year externalizing behaviors was largely by explained by stability in emotion regulation through to 5-years. Although this observation of stability in emotion regulation coupled with associations with externalizing symptoms is significant, as it suggests that emotion regulation processes may be a potential target for early intervention, it also underscores other possible interpretations of our findings. Shared underlying third processes and/or different manifestations of the same problem across development could have yielded similar patterns of results.

Our study is unique in having measured emotion regulation capacities from the neonatal period through to middle childhood. The inclusion of these early observations was informative. Although there was a trend for poorer regulatory capacities to be evident in high risk versus control group neonates in the first month of life, neonatal regulation did not show longitudinal stability even through to 1-year infant age, and did not predict subsequent behavioral problems. ${ }^{6}$ The rudimentary capacities to modulate arousal that are observable in the first three months appear to be largely a function of innate, reflexive mechanisms and individual differences in the physiological parameters underpinning emotional responding (Kopp, 1982; Porges, 1996). More diverse regulatory capacities begin to emerge from around 3-months of age; infants increasingly begin to use social interactions to manage their affective state, a wider repertoire of physical self-soothing behaviors emerges, and the ability to actively utilize cognitive and behavioral engagement/disengagement to regulate arousal develops (Kopp, 1989; Buss \& Goldsmith, 1998; Rothbart, Ziaie, \& O'Boyle, 1992; Stifter \& Braungart, 1995). Further cognitive advances during the second year of life mean that infants begin to understand the source of emotional distress and the actions required to correct it (Kopp, 1989; Cicchetti \& Pogge-Hesse, 1981), and the ability to label emotional states also begins to emerge (Dunn, Bretherton, \& Munn, 1987). Thus, the first years of life bring

\footnotetext{
${ }^{6}$ Although we reported data for combined 12 and 18-month assessments, the pattern was the same when individual assessments were used.
} 
marked changes in both the infant's capacity to regulate emotional states and the mechanisms by which they achieve this. Although we cannot rule out a possible contribution of the inevitable changes in the way that emotion regulation was measured through development, our failure to observe associations between neonatal and subsequent emotion regulation in the current study should be considered in the light of the developmental context outlined: the occurrence of significant transitions in social, cognitive and behavioral capacities, and their application to the management of emotional state, means that discontinuity in regulatory capacities is perhaps to be expected. Moreover, our observations are consistent with previous research which found no stability in the regulation of responses to frustration between 5 and 10-months infant age, but a degree of consistency in regulatory behavior between 10 and 18months (Stifter \& Jain, 1996). Building on this existing work, we were able to demonstrate modest positive associations between emotion regulation capacities measured at 12/18 months and 5-year regulatory capacities, indicating that persistent individual differences in the ability to contain negative emotions may be established by the second year of life.

Consistent with the view that caregivers are a key source of regulatory input for the developing child (Calkins \& Hill, 2007; Kopp, 1982; Tronick \& Gianino, 1986; Thompson \& Meyer, 2007), we observed positive associations between maternal sensitivity and child emotion regulation at every stage of assessment. Moreover, prospective associations were also observed, with maternal sensitivity measured as early as 12-weeks postpartum predicting subsequent emotion regulation. Assessments of child emotion regulation were independent of assessments of parenting in the current study, and therefore associations reflect more than just immediate child responding to maternal input. Although previous research has suggested reciprocal relations between maternal behavior and child characteristics (Patterson, 1995; Cole et al., 2003; van den Boom \& Hoeksma, 1994) our data were consistent with the primacy of the maternal role; thus, while we observed a modest correlation between infancy 
regulation and subsequent maternal sensitivity, this effect was not upheld in path analyses when the full set of longitudinal pathways was examined.

In principle, maternal behavior may influence child regulation of negative emotional states through several mechanisms. In early development, by responding sensitively to their child's emotional state, mothers may provide the child with an appropriate platform from which to learn to regulate their own negative emotions (Cassidy, 1994; Tronick \& Gianino, 1986; Thompson \& Meyer, 2007). Conversely, maternal over-involvement or control may restrict opportunities for the child to learn how to self-regulate, and harsh or insensitive parenting may have a direct adverse impact on child attempts to contain their negative emotions (Calkins \& Johnson, 1998). In later development, mothers may directly teach or model appropriate regulatory behaviors, or may explicitly require or reward effective containment of negative emotions, providing a drive for the child to self-regulate. In addition, responsive maternal behavior may influence the development of underlying child neurophysiological systems key to the expression and containment of emotional responses (Calkins \& Hill, 2007; Moore et al., 2009); tentatively, maternal responses appear to serve as input to the development of child hypothalamic-pituitary-adrenal axis (Murray, Halligan, Goodyer, \& Herbert, 2010; Blair, Granger, Willoughby, \& Kivlighan, 2006; Blair et al., 2008; Gunnar, 1998) and autonomic nervous system functioning (Calkins et al., 2008). Again, we would note that our longitudinal correlations cannot unequivocally establish a causal role for maternal behavior in the development of child emotion regulation; both maternal responding and child emotion regulation may be underpinned by a third variable, such as an unmeasured component of child temperament. Nonetheless, our observations represent an important advance on cross-sectional studies, as they demonstrated an association between early parenting and later child emotion regulation that was maintained even once stability in both these dimensions was taken into account. Future work aimed at 
manipulating aspects of maternal behavior in order to enhance developing child emotion regulation capacities is indicated.

Strikingly, poorer emotion regulation distinguished high versus low risk children at each stage of the study. Moreover, we also observed a strong and persistent association between psychosocial adversity and less sensitive maternal behavior at every stage of assessment, even when longitudinal stability in maternal sensitivity was taken into account in path analyses. In combination, interrelated disturbances in emotion regulation capacities and maternal sensitivity contributed to the association between adversity and child externalizing problems seen at 5-years. Although our analyses utilized groups based on measures of psychosocial adversity taken during the antenatal period, our high adversity group continued to experience multifaceted social difficulties. Thus, at 5-years, compared to their low risk counterparts, high-adversity mothers reported experiencing more socioeconomic deprivation, higher levels of affective symptoms, less satisfactory intimate relationships, poorer housing and higher levels of community disorder, and greater levels of adverse life events (data not presented). Given this high-stress context, and the elevated levels of maternal affective symptoms, associations between ongoing environmental adversity effects and maternal behavior are perhaps unsurprising (Murray et al., 1996; Weissman et al., 2006; Goodman \& Gotlib, 1999). Nonetheless, other explanations are also possible. In principle, the ongoing association between adversity and maternal behavior may reflect stable underlying maternal characteristics which manifest differently at different stages of child development, as adjustment to changing demands is required (Cronin et al., 2008). In this case, the apparently persistent influence of psychosocial adversity on parenting behavior would actually be explained by expression of those characteristics, operating over and above measured stability in parenting. However, the weight of research suggests that parenting is influenced by both such individual characteristics and the quality of the external environment (Kendler \& Baker, 2007). 
Psychosocial adversity was utilized first and foremost as a means of recruiting children at high risk of externalizing problems in the current study; and a comprehensive examination of the components of this multifaceted construct was beyond the scope of this paper. Nonetheless, we conducted exploratory analyses examining whether specific components of adversity might be particularly important. While there was little evidence that maternal antenatal smoking was a significant influence on developing child emotion regulation capacities, maternal age and affective symptomatology did emerge as relatively consistent predictors of emotion regulation outcomes. With respect to the latter component of risk, antenatal symptoms showed the most persistent associations, with higher levels predicting poorer child emotion regulation at every stage of assessment. These observations are consistent with a broader literature linking antenatal maternal stress and depression with multiple adverse child outcomes, including externalizing psychopathology (Van den Bergh, Mulder, Mennes, \& Glover, 2005) and disturbances in the development of emotion regulation capacities (Blandon et al., 2008; Maughan et al., 2007). At the same time, our analyses highlight the difficulties of trying to isolate single contributors to adverse outcomes in high risk populations: as already noted, recruitment for the current study ensured the selection of individuals in whom multiple difficulties tended to co-occur, and observed influences of maternal affective symptoms typically were no longer significant when the broader set of risk factors was considered. Moreover, as with other studies in this area, we would note that although our assessments of psychosocial adversity were relatively comprehensive, there likely remain other factors that distinguished our groups but were not assessed by us (including possible genetic vulnerabilities). Overall, our analyses of the significance of specific components of risk should be interpreted cautiously.

There were important strengths of our study, particularly the high-risk, prospective longitudinal design and the independent assessment of maternal and child characteristics via observational measures. The inclusion of assessments from relatively early in development is 
a second strength, as the first two years of life have been highlighted as a period during which key developments in infant regulatory capacities occur (Kopp, 1989; Rothbart, 1989). The robustness of our study was also improved by the fact that observational assessments were completed at every stage. Nonetheless, our study also had some limitations. First, we included novel assessments to index child regulation of negative emotional responding, albeit with coding schemes based on existing research. The need to standardize measures of child regulation has been noted (Cole, Martin, \& Dennis, 2004), but there is currently no established standard for the measurement of emotion regulation across development. There is also debate in the literature regarding what should be encompassed by the construct of emotion regulation (Thompson, 1994; Cole et al., 2004; Gross \& Thompson, 2007); nevertheless, current definitions consistently emphasize the effectiveness with which affective states are managed and the strategies that are used to achieve this, components which we endeavored to reflect in our assessments. Second, our sample was modest in size, meaning that there was not sufficient power to correct for multiple correlations; and attrition over the six years of study occurred particularly in the high risk group. Although we had no evidence to suggest that families who dropped out of the research were different from those in their group who were retained, the fact that the attrition was largely accounted for due to families being lost to contact may mean that those families experiencing the highest levels of environmental disorder were not included. Finally, although we used a longitudinal approach, ours was still essentially a correlational design. As such, it may be that associations observed between parenting, child regulatory indices, and child behavior are underpinned by shared genetic or other environmental factors. However, processes that are explained by genes are not necessarily immutable, and an insight into interrelationships among different aspects of child disturbance offers potential targets for intervention.

To conclude, our study demonstrated impairments in emotion regulation capacities in children at risk for externalizing disorder that were apparent from an early stage of 
development. Moreover, poorer emotion regulation capacities were longitudinally associated with externalizing difficulties, consistent with a causal role. Persistent maternal insensitivity also characterized high risk dyads, and was longitudinally linked to the development of child emotion regulation problems. In principle, poor emotion regulation capacities may represent a target for (early) intervention, via either directly working to enhance child emotion regulatory skills, or through providing parents with skills to better support their child's emotional development. More broadly, our findings add to a significant literature highlighting links between psychosocial adversity and poorer parental and child functioning, and reaffirm the urgent need to improve outcomes in this context. 
Table 1

Descriptive statistics reported for high and low risk groups

\begin{tabular}{lll}
\hline & $\begin{array}{l}\text { Low risk } \\
(\mathrm{N}=64)\end{array}$ & $\begin{array}{l}\text { High risk } \\
(\mathrm{N}=58)\end{array}$ \\
\hline Antenatal & $M(S D)$ & $M(S D)$ \\
Maternal affective symptoms (HADS) & $7.3(3.3)$ & $14.5(4.9)^{* * *}$ \\
Neonatal & & \\
Self-regulation (NBAS) & $21.6(4.8)$ & $20.0(4.1)^{*}$ \\
Maternal sensitivity & $4.2(0.5)$ & $3.7(0.7)^{* * *}$ \\
Maternal depressive symptoms (EPDS) & $5.5(3.6)$ & $6.8(4.3)$ \\
Infancy & & \\
Emotion regulation & $0.12(0.65)$ & $-0.27(0.70)^{* *}$ \\
Problem behaviors (BSQ) & $0.85(0.53)$ & $1.33(0.70)^{* * *}$ \\
Cognitive abilities (BSID-II MDI) & $94.1(9.8)$ & $90.6(9.8)^{+}$ \\
Maternal sensitivity & $3.61(0.52)$ & $3.07(0.62)^{* * *}$ \\
Maternal affective symptoms (HADS) & $5.9(3.8)$ & $10.7(6.2)^{* * *}$ \\
$\underline{\text { 5-years }}$ & & $10.2(6.0)^{* * *}$ \\
Emotion regulation & $12.18(9.56)$ & $24.7(14.1)^{* * *}$ \\
Externalizing symptoms (SDQ) & $6.5(5.5)$ & $104.0(8.8)^{* * *}$ \\
IQ (WPPSI-R) & $117.9(5.7)$ & $-0.28(0.73)^{* *}$ \\
Maternal sensitivity & $4.0(3.1)$ & $5.7(3.2)^{*}$ \\
Maternal intrusive-control & $116.2(12.8)$ & $100.4(13.9)^{* * *}$ \\
Maternal affective symptoms (HADS) & $4.12(0.65)$ & $3.23(0.94)^{* * *}$ \\
Maternal IQ (NART) & & \\
\hline & & \\
\hline
\end{tabular}

${ }^{+} P<0.10{ }^{*} P<0.05 * * P<0.01 * * * P<0.001$; HADS: Hospital Anxiety and Depression

Scale; NBAS: Neonatal Behavioral Assessment Scales; EPDS: Edinburgh Postnatal

Depression Scale; BSQ: Behavior Screening Questionnaire; BSID-II MDI: Bayley Scales of Infant Development II, Mental Development Index; SDQ: Strengths and Difficulties

Questionnaire; WPPSI-R: Wechsler Preschool and Primary Scale of Intelligence - Revised 
Table 2

Inter-correlations among child emotion regulation scores, behavioral problems, and maternal sensitivity

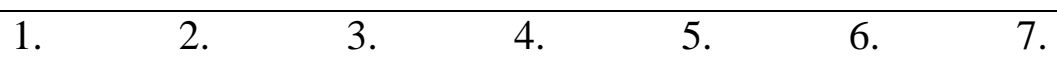

Emotion Regulation

1. Neonatal

2. 12/18-month

.02

3. 5-year

.02

$.27 * *$

Behavioural Problems

4. 12/18-month BSQ

$-.03$

$-.32 * * \quad-.14$

5. 5-year SDQ

$\begin{array}{llll}-.02 & -.34 * * & -.46^{* * *} & .20 \dagger\end{array}$

Maternal Sensitivity
6. 12-week
.15
$.29 *$
$.23 *$
$-.22 * \quad-.36 * * * \quad-$
7. 12/18-month
$-.06$
$.27 * *$
$.26^{*}$
$-.25^{*}$
$-.31 * * \quad .31 * *$
8. 5-year
$-.05$
$.31 * *$
$.37 * * *$
$-.23 *$
$-.42 * * * \quad .20 \dagger$
$.52 * * *$

$\dagger P<0.10^{*} P<0.05 * * P<0.01 * * * P<0.001$; BSQ: Behavior Screening Questionnaire;

SDQ: Strengths and Difficulties Questionnaire. 
Running Head: Emotion regulation and risk for externalizing disorder

Table 3

Correlations maternal age and affective symptoms, and child emotion regulation scores Emotion regulation assessment

Neonatal 12/18-months 5-year

\begin{tabular}{clll}
\hline Affective Symptoms & & & \\
Antenatal (HADS) & $-.25 * *$ & $-.29 * *$ & $-.21^{*}$ \\
Postnatal (EPDS) & $-.28 * *$ & .01 & -.02 \\
12/18-months (HADS) & -.09 & $-.25 *$ \\
5-year (HADS) & & & $-.27 * *$ \\
Maternal age & .02 & $.24 *$ & $.34 * *$ \\
\hline$* P<0.05, * * P<0.01$ & & &
\end{tabular}

HADS: Hospital Anxiety and Depression Scale; EPDS: Edinburgh Postnatal Depression Scale 
Figure 1

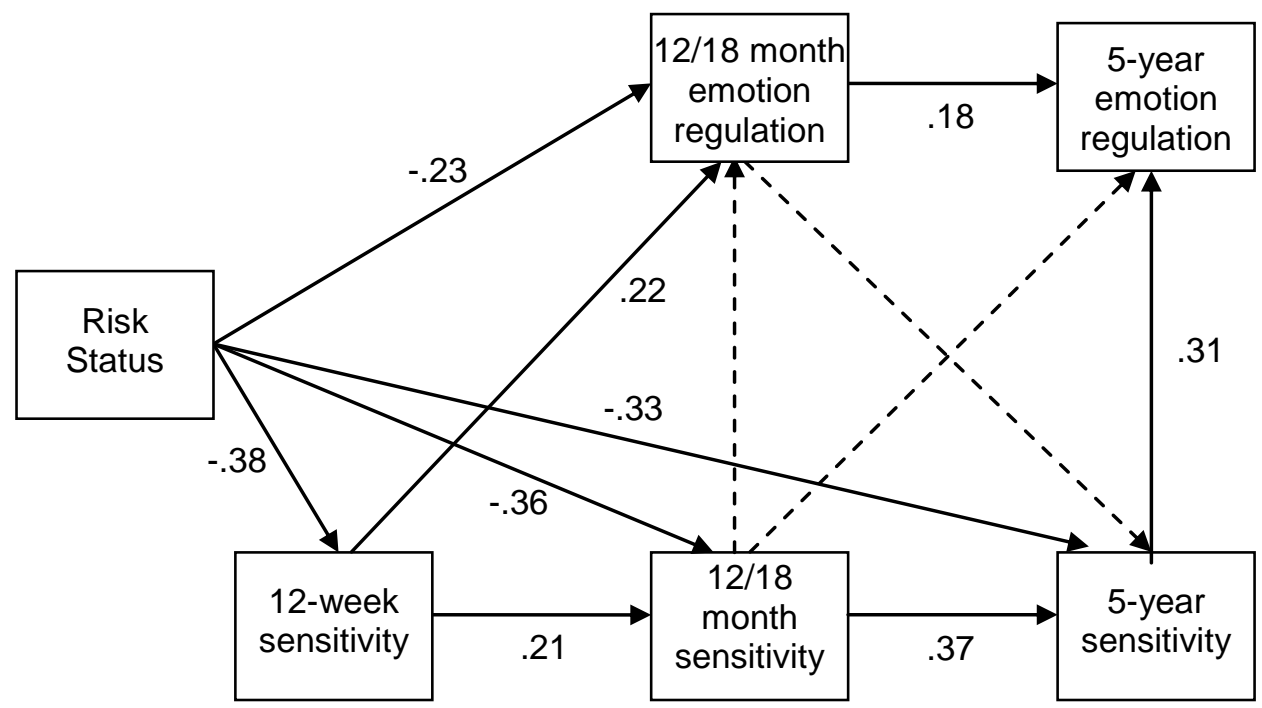


Figure 2

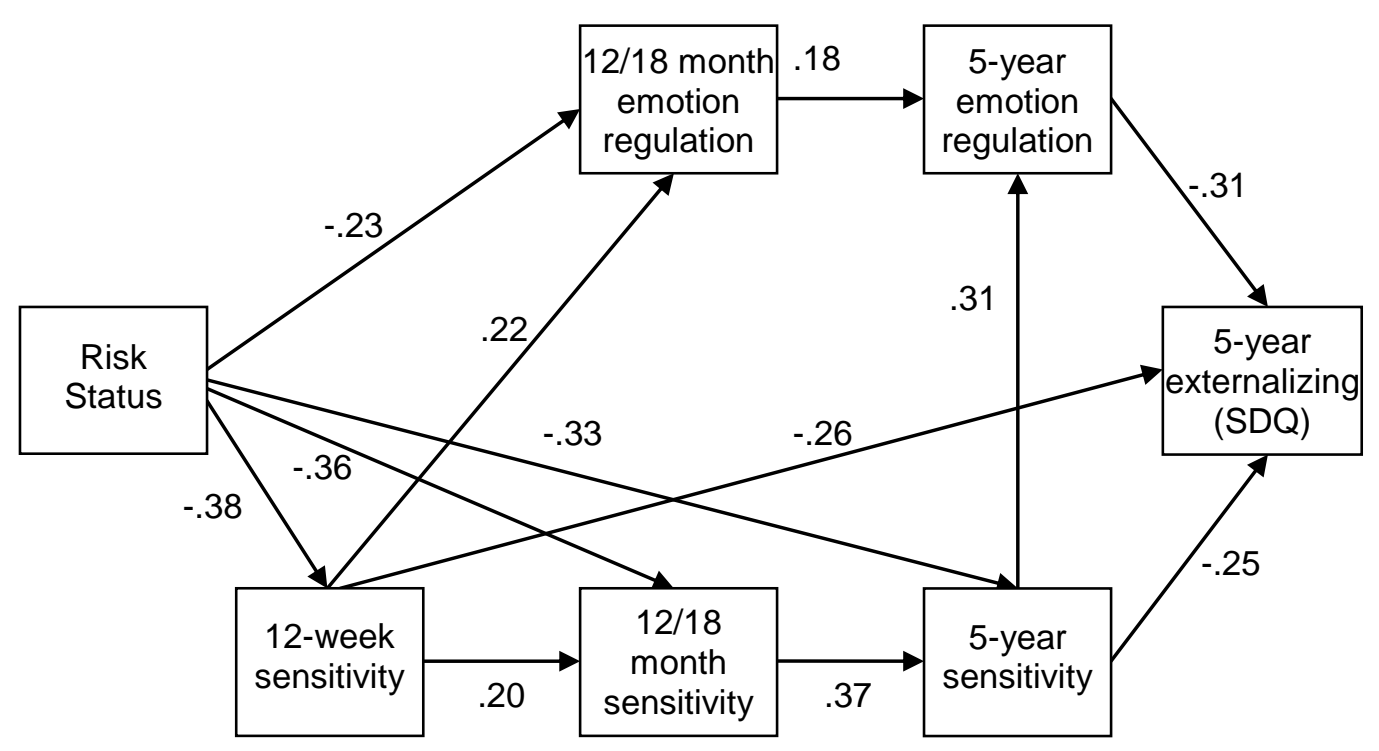


Running Head: Emotion regulation and risk for externalizing disorder

Figure 1 Title

The relationships between risk status, maternal sensitivity and child emotion regulation:

Dashed lines represent non-significant pathways dropped from the original model

Figure 2 Title

Longitudinal pathways from risk status to child externalizing symptoms, via maternal sensitivity and child emotion regulation capacities

Figure 2 Footnote

SDQ: Strengths and Difficulties Questionnaire 
Running Head: Emotion regulation and risk for externalizing disorder

\section{Reference List}

Ainsworth, M. D. S., Blehar, M. C., Waters, E., \& Wall, S. (1978). Patterns of attachment: A psychological study of the strange situation. Hillsdale, New Jersey: Erlbaum.

Allison, P. D. (2003). Missing data techniques for structural equation modeling. Journal of Abnormal Psychology, 112, 545-557.

Barkley, R. A. (1997). ADHD and the Nature of Self-Control. New York, USA: Guilford Press.

Bayley, N. (1993). Bayley Scales of Infant Development - Second Edition. San Antonio, TX: The Psychological Corporation.

Blair, C., Granger, D., Willoughby, M., \& Kivlighan, K. (2006). Maternal sensitivity is related to hypothalamic-pituitary-adrenal axis stress reactivity and regulation in response to emotion challenge in 6-month-old infants. Annals of the New York Academy of Science, 1094, 263-267.

Blair, C., Granger, D. A., Kivlighan, K. T., Mills-Koonce, R., Willoughby, M., Greenberg, M. T. et al. (2008). Maternal and Child Contributions to Cortisol Response to Emotional Arousal in Young Children From Low-Income, Rural Communities. Developmental Psychology, 44, 1095-1109.

Blandon, A. Y., Calkins, S. D., Keane, S. P., \& O'Brien, M. (2008). Individual differences in trajectories of emotion regulation processes: the effects of maternal depressive symptomatology and children's physiological regulation. Developmental Psychology, 44, $1110-1123$.

Brazelton, T. B. \& Nugent, J. K. (1995). The Neonatal Behavioural Assessment Scale. (3rd ed.) London: MacKeith Press.

Bright, P., Jaldow, E., \& Kopelman, M. D. (2002). The National Adult Reading Test as a measure of premorbid intelligence: a comparison with estimates derived from demographic variables. Journal of the International Neuropsychological Society, 8, 847-854.

Buss, K. A. \& Goldsmith, H. H. (1998). Fear and anger regulation in infancy: effects on the temporal dynamics of affective expression. Child Development, 69, 359-374.

Calkins, S. D. (1994). Origins and outcomes of individual differences in emotion regulation. In N.A.Fox (Ed.), Emotion regulation: Behavioral and biological consequences (59 ed., pp. 53-72). 
Calkins, S. D. \& Dedmon, S. E. (2000). Physiological and behavioral regulation in two-year-old children with aggressive/destructive behavior problems. Journal of Abnormal Child Psychology, 28, 103-118.

Calkins, S. D., Graziano, P. A., Berdan, L. E., Keane, S. P., \& Degnan, K. A. (2008). Predicting cardiac vagal regulation in early childhood from maternal-child relationship quality during toddlerhood. Developmental Psychobiology, 50, 751-766.

Calkins, S. D. \& Hill, A. (2007). Caregiver influences on emerging emotion regulation: Biological and environmental transactions in early development. In J.J.Gross (Ed.), The Handbook of Emotion Regulation (pp. 229-248). New York, NY: Guilford Press.

Calkins, S. D. \& Johnson, M. C. (1998). Toddler regulation of distress to frustrating events: Temperamental and maternal correlates. Infant Behavior and Development, 21, 349357.

Calkins, S. D. \& Keane, S. P. (2004). Cardiac vagal regulation across the preschool period: stability, continuity, and implications for childhood adjustment. Developmental Psychobiology, 45, 101-112.

Calkins, S. D. \& Keane, S. P. (2009). Developmental origins of early antisocial behavior. Development and Psychopathology, 21, 1095-1109.

Campbell, S. B. (2002). Behavior Problems in Preschool Children: Clinical and Developmental Issues. New York: Guilford Press.

Cassidy, J. (1994). Emotion regulation: influences of attachment relationships. Monographs of the Society for Research in Child Development, 59, 228-249.

Charles, S. T. \& Carstensen, L. L. (2007). Emotion regulation and aging. In J.J.Gross (Ed.), The Handbook of Emotion Regulation (pp. 307-327). New York: The Guilford Press.

Cicchetti, D., Ackerman, B. P., \& Izard, C. E. (1995). Emotions and Emotion Regulation in Developmental Psychopathology. Development and Psychopathology, 7, 1-10.

Cicchetti, D. \& Pogge-Hesse, P. (1981). The relation between emotion and cognition in infant development. In M.Lamb \& L. Sherrod (Eds.), Infant Social Cognition (pp. 205272). Hillsdale, NJ: Erlbaum.

Cole, P. M., Martin, S. E., \& Dennis, T. A. (2004). Emotion regulation as a scientific construct: methodological challenges and directions for child development research. Child Development, 75, 317-333.

Cole, P. M., Michel, M. K., \& Teti, L. O. (1994). The development of emotion regulation and dysregulation: a clinical perspective. Monographs of the Society for Research in Child Development, 59, 73-100. 
Cole, P. M., Teti, L. O., \& Zahn-Waxler, C. (2003). Mutual emotion regulation and the stability of conduct problems between preschool and early school age. Development and Psychopathology, 15, 1-18.

Cole, P. M., Wiggins, C. N., Radzioch, A. M., \& Pearl, A. M. (2007). D.O.T.S. Emotion Coding System. Department of Psychology, Pennsylvania State University.

Cole, P. M., Zahn-Waxler, C., Fox, N. A., Usher, B. A., \& Welsh, J. D. (1996). Individual differences in emotion regulation and behavior problems in preschool children. Journal of Abnormal Psychology, 105, 518-529.

Cole, P. M., Zahn-Waxler, C., \& Smith, K. D. (1994). Expressive control during a disappointment: Variations related to preschoolers' behavior problems. Developmental Psychology, 30, 835-846.

Conradt, E. \& Ablow, J. (2010). Infant physiological response to the still-face paradigm: contributions of maternal sensitivity and infants' early regulatory behavior. Infant Behavior and Development, 33, 251-265.

Cox, J. L., Holden, J. M., \& Sagovsky, R. (1987). Detection of postnatal depression. Development of the 10-item Edinburgh Postnatal Depression Scale. British Journal of Psychiatry, 150, 782-786.

Cronin, A., Halligan, S. L., \& Murray, L. (2008). Maternal psychosocial adversity and the longitudinal development of infant sleep. Infancy, 13, 469-495.

Dadds, M. R., Mullins, M. J., McAllister, R. A., \& Atkinson, E. (2003). Attributions, affect, and behavior in abuse-risk mothers: a laboratory study. Child Abuse and Neglect, 27, $21-45$.

Deater-Deckard, K., Petrill, S. A., \& Thompson, L. A. (2007). Anger/frustration, task persistence, and conduct problems in childhood: a behavioral genetic analysis. Journal of Child Psychology and Psychiatry, 48, 80-87.

DiPietro, J. A., Hodgson, D. M., Costigan, K. A., \& Johnson, T. R. (1996). Fetal antecedents of infant temperament. Child Development, 67, 2568-2583.

Dunn, J., Bretherton, I., \& Munn, P. (1987). Conversations about feeling states between mothers and their young children. Developmental Psychology, 23, 132-139.

Eisenberg, N., Fabes, R. A., Murphy, B., Maszk, P., Smith, M., \& Karbon, M. (1995). The role of emotionality and regulation in children's social functioning: a longitudinal study. Child Development, 66, 1360-1384.

Eisenberg, N., Smith, C. L., Sadovsky, A., \& Spinrad, T. L. (2004). Effortful control: Relations with emotion regulation, adjustment, and socialization in childhood. In 
R.F.Baumeister \& K. D. Vohs (Eds.), Handbook of Self-Regulation: Research, Theory, and Applications (pp. 259-282). New York: Guilford Press.

Eisenberg, N., Zhou, Q., Spinrad, T. L., Valiente, C., Fabes, R. A., \& Liew, J. (2005). Relations among positive parenting, children's effortful control, and externalizing problems: a three-wave longitudinal study. Child Development, 76, 1055-1071.

Feng, X., Shaw, D. S., Kovacs, M., Lane, T., O'Rourke, F. E., \& Alarcon, J. H. (2008). Emotion regulation in preschoolers: the roles of behavioral inhibition, maternal affective behavior, and maternal depression. Journal of Child Psychology and Psychiatry, 49, 132-141.

Fergusson, D. M., Horwood, L. J., \& Lynskey, M. T. (1993). Maternal smoking before and after pregnancy: effects on behavioral outcomes in middle childhood. Pediatrics, 92, 815-822.

Fergusson, D. M. \& Lynskey, M. T. (1993). Maternal age and cognitive and behavioural outcomes in middle childhood. Paediatric and Perinatal Epidemiology, 7, 77-91.

Fergusson, D. M. \& Woodward, L. J. (1999). Maternal Age and Educational and Psychosocial Outcomes in Early Adulthood. Journal of Child Psychology and Psychiatry, 40, 479-489.

Field, T., Diego, M., \& Hernandez-Reif, M. (2006). Prenatal depression effects on the fetus and newborn: a review. Infant Behavior and Development, 29, 445-455.

Fried, P. A. \& Makin, J. E. (1987). Neonatal behavioural correlates of prenatal exposure to marihuana, cigarettes and alcohol in a low risk population. Neurotoxicology and Teratology, 9, 1-7.

Gardner, F. E., Sonuga-Barke, E. J., \& Sayal, K. (1999). Parents anticipating misbehaviour: an observational study of strategies parents use to prevent conflict with behaviour problem children. Journal of Child Psychology and Psychiatry, 40, 1185-1196.

Ghodsian, M., Zajicek, E., \& Wolkind, S. (1984). A Longitudinal-Study of Maternal Depression and Child-Behavior Problems. Journal of Child Psychology and Psychiatry, 25, 91-109.

Gilliom, M., Shaw, D. S., Beck, J. E., Schonberg, M. A., \& Lukon, J. L. (2002). Anger regulation in disadvantaged preschool boys: strategies, antecedents, and the development of self-control. Developmental Psychology, 38, 222-235.

Goldsmith, H. H., Buss, K. A., \& Lemery, K. S. (1997). Toddler and childhood temperament: expanded content, stronger genetic evidence, new evidence for the importance of environment. Developmental Psychology, 33, 891-905. 
Goldsmith, H. H. \& Rothbart, M. K. (1999). The Laboratory Temperament Assessment Battery: Locomotor Version. University of Wisconsin/University of Oregon.

Goodman, R. (1997). The Strengths and Difficulties Questionnaire: a research note. Journal of Child Psychology and Psychiatry, 38, 581-586.

Goodman, R., Ford, T., Simmons, H., Gatward, R., \& Meltzer, H. (2000). Using the Strengths and Difficulties Questionnaire (SDQ) to screen for child psychiatric disorders in a community sample. British Journal of Psychiatry, 177, 534-539.

Goodman, S. H. \& Gotlib, I. H. (1999). Risk for psychopathology in the children of depressed mothers: a developmental model for understanding mechanisms of transmission. Psychological Review, 106, 458-490.

Gross, J. J. \& Thompson, R. A. (2007). Emotion regulation: conceptual foundations. In J.J.Gross (Ed.), The Handbook of Emotion Regulation (pp. 3-24). New York: The Guilford Press.

Gunnar, M. R. (1998). Quality of early care and buffering of neuroendocrine stress reactions: potential effects on the developing human brain. Preventive Medicine, 27, 208-211.

Gunning, M., Conroy, S., Valoriani, V., Figueiredo, B., Kammerer, M. H., Muzik, M. et al. (2004). Measurement of mother-infant interactions and the home environment in a European setting: preliminary results from a cross-cultural study. British Journal of Psychiatry Supplement, 46, s38-s44.

Hinshaw, S. P. (2003). Impulsivity, emotion regulation, and developmental psychopathology: specificity versus generality of linkages. Annals of the New York Academy of Science, 1008, 149-159.

Huffman, L. C., Bryan, Y. E., del, C. R., Pedersen, F. A., Doussard-Roosevelt, J. A., $\&$ Porges, S. W. (1998). Infant temperament and cardiac vagal tone: assessments at twelve weeks of age. Child Development, 69, 624-635.

John, O. P. \& Gross, J. J. (2007). Individual differences in emotion regulation. In J.J.Gross (Ed.), The Handbook of Emotion Regulation (pp. 351-372). New York: The Guilford Press.

Kendler, K. S. \& Baker, J. H. (2007). Genetic influences on measures of the environment: a systematic review. Psychological Medicine, 37, 615-626.

Kim, J. \& Cicchetti, D. (2010). Longitudinal pathways linking child maltreatment, emotion regulation, peer relations, and psychopathology. Journal of Child Psychology and Psychiatry, 51, 706-716. 
Kochanska, G. \& Knaack, A. (2003). Effortful control as a personality characteristic of young children: antecedents, correlates, and consequences. Journal of Personality, 71, 1087-1112.

Kopp, C. B. (1982). Antecedents of self-regulation: A developmental perspective. Developmental Psychology, 18, 199-214.

Kopp, C. B. (1989). Regulation of distress and negative emotions: A developmental view. Developmental Psychology, 25, 343-354.

Marsee, M. A. \& Frick, P. J. (2007). Exploring the cognitive and emotional correlates to proactive and reactive aggression in a sample of detained girls. Journal of Abnormal Child Psychology, 35, 969-981.

Marshall, P. J., Fox, N. A., \& Henderson, H. A. (2002). Temperament as an organizer of development. Infancy, 1, 1199-1208.

Maughan, A., Cicchetti, D., Toth, S. L., \& Rogosch, F. A. (2007). Early-occurring maternal depression and maternal negativity in predicting young children's emotion regulation and socioemotional difficulties. Journal of Abnormal Child Psychology, 35, 685703.

Melnick, S. M. \& Hinshaw, S. P. (2000). Emotion regulation and parenting in AD/HD and comparison boys: linkages with social behaviors and peer preference. Journal of Abnormal Child Psychology, 28, 73-86.

Mesman, J., van IJzendoorn, M. H., \& Bakermans-Kranenburg, M. J. (2009). The many faces of the Still-Face Paradigm: A review and meta-analysis. Developmental Review, 29, 120-162.

Moore, G. A., Hill-Soderlund, A. L., Propper, C. B., Calkins, S. D., Mills-Koonce, W. R., \& Cox, M. J. (2009). Mother-infant vagal regulation in the face-to-face still-face paradigm is moderated by maternal sensitivity. Child Development, 80, 209-223.

Morrell, J. \& Murray, L. (2003). Parenting and the development of conduct disorder and hyperactive symptoms in childhood: a prospective longitudinal study from 2 months to 8 years. Journal of Child Psychology and Psychiatry, 44, 489-508.

Murray, L. (1992). The impact of postnatal depression on infant development. Journal of Child Psychology and Psychiatry, 33, 543-561.

Murray, L., FioriCowley, A., Hooper, R., \& Cooper, P. (1996). The impact of postnatal depression and associated adversity on early mother-infant interactions and later infant outcome. Child Development, 67, 2512-2526. 
Murray, L., Halligan, S. L., Goodyer, I., \& Herbert, J. (2010). Disturbances in early parenting of depressed mothers and cortisol secretion in offspring: a preliminary study. Journal of Affective Disorders, 122, 218-223.

Nelson, H. \& Willison, J. (1991). National Adult Reading Test (NART). (2nd ed.) Windsor: NFER-Nelson.

O'Connor, T. G., Deater-Deckard, K., Fulker, D., Rutter, M., \& Plomin, R. (1998). Genotype-environment correlations in late childhood and early adolescence: antisocial behavioral problems and coercive parenting. Developmental Psychology, 34, 970-981.

Patterson, G. R. (1995). Coercion - a basis for early age of onset for arrest. In D.J.Pepler \& K. H. Rubin (Eds.), The Development and Treatment of Childhood Aggression (pp. 81-105). New York: Cambridge University Press.

Porges, S. W. (1996). Physiological regulation in high-risk infants: A model for assessment and potential intervention. Development and Psychopathology, 8, 43-58.

Porges, S. W., Doussard-Roosevelt, J. A., \& Maiti, A. K. (1994). Vagal tone and the physiological regulation of emotion. Monographs of the Society for Research in Child Development, 59, 167-186.

Preacher, K. J. \& Hayes, A. F. (2008). Asymptotic and resampling strategies for assessing and comparing indirect effects in multiple mediator models. Behavior Research Methods, 40, 879-891.

Raiha, H., Lehtonen, L., Huhtala, V., Saleva, K., \& Korvenranta, H. (2002). Excessively crying infant in the family: mother-infant, father-infant and mother-father interaction. Child: Care, Health and Development, 28, 419-429.

Richman, N. \& Graham, P. J. (1971). A Behavioural Screening Questionnaire for use with three-year-old children: preliminary findings. Journal of Child Psychology and Psychiatry, 12, 5-33.

Rothbart, M. K. (1989). Temperament and development. In G.A.Kohnstamm, J. A. Bates, \& M. K. Rothbart (Eds.), Temperament in Childhood (pp. 187-247). New York: Wiley.

Rothbart, M. K. \& Derryberry, D. (1981). Development of individual differences in temperament. In M.Lamb \& A. Brown (Eds.), Advances in Developmental Psychology (pp. 37-86). Hillsdale, NJ: Erlbaum.

Rothbart, M. K., Ziaie, H., \& O'Boyle, C. (1992). Self-regulation and emotion in infancy. In N.Eisenberg \& R. A. Fabes (Eds.), Emotion and its Regulation in Early Development (pp. 7-23). San Francisco: Jossey-Bass/Pfeiffer. 
Rutter, M., Giller, H., \& Hagell, A. (1998). Antisocial Behavior by Young People. Cambridge, England: Cambridge University Press.

Satorra, A. \& Bentler, P. M. (2001). A scaled difference chi-square test statistic for moment structure analysis. Psychometrika, 66, 507-514.

Schafer, J. L. \& Graham, J. W. (2002). Missing data: our view of the state of the art. Psychological Methods, 7, 147-177.

Schuetze, P., Lopez, F. A., Granger, D. A., \& Eiden, R. D. (2008). The association between prenatal exposure to cigarettes and cortisol reactivity and regulation in 7-month-old infants. Developmental Psychobiology, 50, 819-834.

Shaw, D. S., Gilliom, M., Ingoldsby, E. M., \& Nagin, D. S. (2003). Trajectories leading to school-age conduct problems. Developmental Psychology, 39, 189-200.

Shaw, D. S., Winslow, E. B., Owens, E. B., \& Hood, N. (1998). Young children's adjustment to chronic family adversity: a longitudinal study of low-income families. Journal of the American Academy of Child and Adolescent Psychiatry, 37, 545-553.

Shields, A. \& Cicchetti, D. (1998). Reactive aggression among maltreated children: the contributions of attention and emotion dysregulation. Journal of Clinical Child Psychology, 27, 381-395.

Stifter, C. A. \& Braungart, J. M. (1995). The regulation of negative reactivity in infancy: Function and development. Developmental Psychology, 31, 448-455.

Stifter, C. A. \& Jain, A. (1996). Psychophysiological correlates of infant temperament: stability of behavior and autonomic patterning from 5 to 18 months. Developmental Psychobiology, 29, 379-391.

Talge, N. M., Neal, C., \& Glover, V. (2007). Antenatal maternal stress and long-term effects on child neurodevelopment: how and why? Journal of Child Psychology and Psychiatry, 48, 245-261.

Thompson, R. (1994). Emotion regulation: A theme in search of definition. Monographs of the Society for Research in Child Development, 59, 25-52.

Thompson, R. A. \& Meyer, S. (2007). Socialization of emotion regulation in the family. In J.J.Gross (Ed.), The Handbook of Emotion Regulation (pp. 249-268). New York, NY: Guilford Press.

Tronick, E. Z. \& Gianino, A. (1986). Interactive mismatch and repair: Challenges to the coping infant. Zero to Three: Bulletin of the National Center for Clinical Infant Programs, 6, 1-6. 
Van den Bergh, B. R., Mulder, E. J., Mennes, M., \& Glover, V. (2005). Antenatal maternal anxiety and stress and the neurobehavioural development of the fetus and child: links and possible mechanisms. A review. Neuroscience and Biobehavioral Reviews, 29, 237258.

van den Boom, D. C. \& Hoeksma, J. B. (1994). The effect of infant irritability on mother-infant interaction: A growth curve analysis. Developmental Psychology, 30, 581-590.

Walcott, C. M. \& Landau, S. (2004). The relation between disinhibition and emotion regulation in boys with attention deficit hyperactivity disorder. Journal of Clinical Child and Adolescent Psychology, 33, 772-782.

Weissman, M. M., Pilowsky, D. J., Wickramaratne, P. J., Talati, A., Wisniewski, S. R., Fava, M. et al. (2006). Remissions in maternal depression and child psychopathology: a STAR*D-child report. Journal of the Amercian Medical Association, 295, 1389-1398.

Weitzman, M., Gortmaker, S., \& Sobol, A. (1992). Maternal smoking and behavior problems of children. Pediatrics, 90, 342-349.

Wolke, D., Skuse, D., \& Mathisen, B. (1990). Behavioral style in failure-to-thrive infants: a preliminary communication. Journal of Pediatric Psychology, 15, 237-254.

Woodward, L. J., Horwood, L. J., \& Fergusson, D. M. (2001). Teenage pregnancy: cause for concern. New Zealand Medical Journal, 114, 301-303.

Zigmond, A. S. \& Snaith, R. P. (1983). The hospital anxiety and depression scale. Acta Psychiatrica Scandinavica, 67, 361-370. 